\title{
Studies of ozone initiated reactions of gaseous mercury: kinetics, product studies, and atmospheric implications
}

\author{
Biswajit Pal and Parisa A. Ariya
}

\begin{abstract}
Kinetics of $\mathrm{O}_{3}$ initiated oxidation reaction of $\mathrm{Hg}^{0}$ was performed in $\mathrm{N}_{2}$ and over the temperature range of $283-323 \mathrm{~K}$ at pressure of $750 \pm 1 \mathrm{Torr}$, in order to provide further understanding of geochemical mercury cycling. Kinetic studies were carried out using relative and absolute techniques by gas chromatography with mass spectroscopy (GC-MS). The room temperature reaction rate constant was determined to be $(7.5 \pm 0.9) \times 10^{-19} \mathrm{~cm}^{3}$ molecule ${ }^{-1} \mathrm{~s}^{-1}$. The calculated activation energy $\left(E_{\underline{\mathrm{A}}}\right)$ and pre-exponential factor $(A)$ were $11.7 \pm 0.27 \mathrm{~kJ} \mathrm{~mol}^{-1}$ and $8.43 \times$ $10^{-17} \mathrm{~cm}^{3}$ molecule $\mathrm{s}^{-1}$, respectively. For the first time, products of $\mathrm{O}_{3}$-initiated oxidation of elemental mercury have been studied in the gas-phase, from the suspended aerosols, and from the wall of the reactor, using chemical ionization mass spectrometry (CI-MS), GC-MS, and inductively coupled plasma mass spectrometry (ICP-MS). Under our experimental conditions, the dominant identified product was $\mathrm{HgO}$, which was mainly adsorbed on the reaction walls, and there was less than $1 \%$ of the reaction product collected on the micron filters $(0.5 \mu)$ from the suspended aerosols. The implications of our kinetics and product studies to the chemistry of the atmosphere are herein discussed.
\end{abstract}

\section{Introduction}

$\mathrm{Hg}^{0}$ was assumed to have a relatively long lifetime in the troposphere. $\frac{1-3}{\text { It }}$ is emitted to the atmosphere from a variety of natural and anthropogenic sources, and is removed through dry and wet deposition processes..$^{\underline{3}}$ However, interestingly, in the high-Arctic, $\stackrel{46}{-}$ sub-Arctic,,$\underline{7}$ and Antarctica,, the rapid depletion of elemental mercury has been observed which coincides with near total depletion of ozone. This ozone depletion at the ground is assumed to be driven by sunlight and bromine atoms derived from reactions of atmospheric reactive halogens with marine sea salt in surface snow and ice. .12 Mercury depletion events are influenced by the photochemical oxidation of elemental mercury in the troposphere involving sea salt on snow/icepack or aerosols. $\frac{13.14}{14}$ Unlike most of the other heavy metals, mercury and many of its compounds behave exceptionally in the atmosphere due to their semi-volatility, capability for methylation, and subsequent bioaccumulation in the aquatic food chain. $\frac{15}{\mathrm{Hg}^{0}}$ exists in ambient air both in the vapor and particle phase associated with aerosols. The background concentration of atmospheric $\mathrm{Hg}^{0}$ in the lower troposphere of the Northern Hemisphere and the Southern Hemisphere, which is mainly in elemental mercury, is around 1.3 to $1.7 \mathrm{ng} \mathrm{m}^{-3}$, respectively. $\frac{16-18}{}$ Recently it has been reported 19 that fast oxidation of gaseous elemental mercury leads to variable $\mathrm{Hg}^{0}$ concentrations during Antarctic summer, accompanied by elevated concentrations, up to more than $300 \mathrm{pg} \mathrm{m}^{-3}$, of reactive gaseous mercury.

Unlike the reactions of $\mathrm{Hg}^{0}$ in solution, many gaseous reactions of mercury with atmospherically important oxidants are difficult to investigate experimentally due to small concentrations of species at atmospheric conditions, low volatility of products, and strong effects of water vapor and surface on kinetics. The chemistry of atmospheric mercury suggested that 
(C) 2004 the Owner Societies (Royal Society of Chemistry)

https://pubs.rsc.org/en/content/articlelanding/2004/cp/b311150d/unauth

photochemical processes may be important for the production of oxidized mercury species and $\mathrm{Hg}^{0}$ oxidation processes are accelerated in the presence of water, although no specific pathways

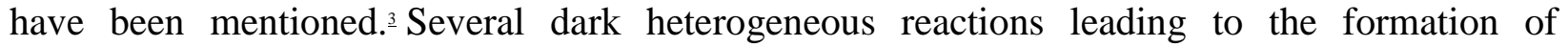
reactive halogens have been suggested (e.g., generation of $\mathrm{Br}_{2}$ via the oxidation of $\mathrm{Br}^{-}$by $\mathrm{O}_{3}^{20}$ ). The halogen atoms can react directly with mercury or through their further reaction with ozone form halogen oxide radicals $\left(\mathrm{BrO}^{*} / \mathrm{ClO}^{*}\right)$, which undergo reaction with elemental mercury transfer to oxidized mercury species.21 The primary halogen atoms $(\mathrm{Br} / \mathrm{Cl})$ and molecular halogens $\left(\mathrm{Br}_{2} / \mathrm{Cl}_{2}\right)$ may also oxidize elemental mercury to $\mathrm{HgBr}_{2}$, and $\mathrm{HgCl}_{2}$, respectively, a subject studied in this laboratory. ${ }^{22.23}$ Some possible reactions of elemental $\mathrm{Hg}^{0}$ with a variety of atmospheric oxidants and reductants have been investigated 24 by using their thermodynamic data, suggesting that $\mathrm{O}_{3}$ and $\mathrm{Cl}_{2}$ may be important oxidants of $\mathrm{Hg}^{0}$, while $\mathrm{SO}_{2}$ and $\mathrm{CO}$ may be important reductants of $\mathrm{Hg}$ (II). Both oxidation of $\mathrm{Hg}^{0}$ and reduction of $\mathrm{Hg}(\mathrm{II})$ by $\mathrm{H}_{2} \mathrm{O}_{2}$ are thermodynamically favorable, ${ }^{25}$ although previous studies 26 have indicated that the oxidation of $\mathrm{Hg}^{0}$ by $\mathrm{H}_{2} \mathrm{O}_{2}$ may be unlikely. Recently, some researchers ${ }^{27-29}$ have studied the kinetics of various mercury species with free radicals (e.g., $\mathrm{HO}^{\circ}, \mathrm{HO}_{2}{ }^{\circ}$, and $\mathrm{NO}_{3}{ }^{\circ}$ ).

Background concentrations of $\mathrm{O}_{3}$ in the atmosphere are about 20-30 parts-per-billion ( $\mathrm{ppb}=$ $2.46 \times 10^{10}$ molecule $\left.\mathrm{cm}^{-3}\right)^{30}$ and can peak to several hundred ppb in urban areas. Since ozone is one of the most predominant atmospheric oxidants, it is important to evaluate the direct impact of gaseous $\mathrm{O}_{3}$-initiated oxidation reactions of mercury in the chemistry of global atmosphere. Several authors ${ }^{31.32}$ have studied the kinetics of the aqueous phase reaction of elemental mercury with $\mathrm{O}_{3}$. The corresponding gas phase reactions have been studied ${ }^{30.33 .34}$ indicating that the $\mathrm{O}_{3}$-initiated reaction of $\mathrm{Hg}^{0}$ is more dominant in the stratosphere due to high $\mathrm{O}_{3}$ concentrations. The rate constant for the gas phase reaction of $\mathrm{Hg}^{0}$ and $\mathrm{O}_{3}$ has been estimated to be in a range of $4.2 \times$ $10^{-19}$ to $4.9 \times 10^{-18} \mathrm{~cm}^{3}$ molecule $\mathrm{s}^{-1}$ (at $293 \mathrm{~K}$ ),.2.24 This range has been obtained based on experimental data of P'yankov. ${ }^{33}$ In another study, ${ }^{31}$ the calculated rate constant has been estimated to be $1.7 \times 10^{-18} \mathrm{~cm}^{3}$ molecule $\mathrm{e}^{-1} \mathrm{~s}^{-1}$ (at $293 \mathrm{~K}$ ). Hall ${ }^{30}$ re-investigated the kinetics of gasphase oxidation of $\mathrm{Hg}^{0}$ by $\mathrm{O}_{3}$ and reported a rate constant of $3.0 \times 10^{-20} \mathrm{~cm}^{3}$ molecule $\mathrm{c}^{-1} \mathrm{~s}^{-1}$, which is much slower than the previously reported values. The limited number of temperature dependent kinetic studies and the large uncertainties in the rate constant values, in addition to lack of any previous product studies, reflect the essence to perform the present research.

In this study, we carried out kinetics and product studies of gas phase reactions of elemental mercury with ozone over the temperature range 283-323 $\mathrm{K}$ in $\mathrm{N}_{2}$ under near tropospheric conditions using gas chromatography with mass spectroscopic detection (GC-MS), chemical ionization mass spectrometry (CI-MS), and inductively coupled plasma mass spectroscopy (ICPMS).

\section{Experimental}

\subsection{Kinetics}

The rate constants of $\mathrm{O}_{3}$-initiated reactions of $\mathrm{Hg}^{0}$ were determined using relative and absolute rate techniques by gas chromatography with mass spectroscopic detection (GC-MS). The experiments were performed under near atmospheric pressure (750 \pm 1 Torr) over the temperature range 283$323 \mathrm{~K} . \mathrm{N}_{2}$ was used as diluent gas. The quoted uncertainties in the tables correspond to two standard deviations from least-squares fits. However, the errors of the final kinetic data given in the text represent accumulative uncertainties derived from the least-squares fits $(0.5-10 \%)$, instrumental $(>10 \%)$, concentration measurements $(>5 \%)$, and due to adsorption $(>5 \%)$. 
(C) 2004 the Owner Societies (Royal Society of Chemistry)

https://pubs.rsc.org/en/content/articlelanding/2004/cp/b311150d/unauth

The experiments were carried out in relatively small temperature-controlled 2-5 L double walled Pyrex vessels equipped with magnetic stirrers to assure homogeneous mixing. The temperature of the vessel was controlled by circulating water through the outer jacket using a circulator (Neslab RTE 111). The temperature was kept constant to $\pm 1 \mathrm{~K}$ over the temperature range 283-323 K. In order to prevent undesirable wall reactions of reagents on the flask, the reaction chamber was coated with halocarbon wax (Supelco). To prepare reaction mixtures, the reaction chamber was evacuated to a pressure of $c a \cdot 10^{-4}$ Torr by using a vacuum system. $\mathrm{N}_{2}$ saturated with mercury vapor was transferred to the evacuated flask to approximately 400 Torr. The total pressure was then raised to about 750 Torr by addition of $\mathrm{N}_{2}$. The other reactants were directly injected using liquid (Hamilton series 700 Micro liter) or gas-tight syringes (Hamilton series 1800 Gas tight).

A GC-MS was used to monitor the concentrations of mercury and the reference molecule by MS detection (quadrupole MSD, HP 5973) after separation on a gas chromatograph (HP6890) equipped with a $0.25 \mathrm{~mm}$ id $\times 30 \mathrm{~m}$ crossed-linked phenyl-methyl-siloxane column (HP5-MS). The column was operated at a constant flow $\left(1.5 \mathrm{ml} \mathrm{min}^{-1}\right)$ of helium and was kept isothermal at $40{ }^{\circ} \mathrm{C}$ for $1 \mathrm{~min}$. During the chromatographic runs, the oven temperature was increased at $25{ }^{\circ} \mathrm{C}$ $\mathrm{min}^{-1}$ from 40 to $150{ }^{\circ} \mathrm{C}$. Since the concentration of $\mathrm{Hg}^{0}$ is low enough, the kinetics was followed using the single ion-monitoring (SIM) mode. However, before that, each kinetic run was monitored in the scanning mode of the MSD. The $\mathrm{m} / \mathrm{z}$ values to be monitored by the mass spectrometer were selected based on their relatively high abundance in the mass spectra of the reference or reactant compounds. Mercury ions with $\mathrm{m} / z$ 199, 200, 201, and 202 were monitored in the SIM mode. The observed isotopic ratios for these corresponded ions are well in agreement with the expected, 56 : $78: 44: 100$. Based on the temperature of the column mentioned above, the measured retention time of the mercury peak was from 1.39 to $1.41 \mathrm{~min}$. The detection limit of $\mathrm{Hg}^{0}$ was $10 \mathrm{ppb}$.

The kinetic system appeared to be very sensitive to the nature of the wall. Therefore, to decrease the significance of surface reactions, the inside walls of the reaction chamber were coated with halocarbon wax. Moreover, the reactant mixture was always given sufficient time to saturate the walls before the $\mathrm{O}_{3}$ was introduced and measurement were started. Several wall loss measurements were performed for both $\mathrm{Hg}^{0}$ and $\mathrm{O}_{3}$ throughout the equilibrium and reaction time. Experiment showed that the rate of wall losses of $\mathrm{Hg}^{0}\left(k^{\mathrm{Hg}}\right.$ ads $)$ at $298 \mathrm{~K}$ in $c a .0 .4 \mathrm{~cm}^{-1} \mathrm{~s} / \mathrm{v}$ ratio is $2.4 \times$ $10^{-3} \mathrm{~min}^{-1}$ (where $\left[\mathrm{Hg}^{0}\right]=0.5 \mathrm{ppm}$ ) and the decrease in concentration is $\mathrm{ca} .4 .5 \%$ in $30 \mathrm{~min}$. After nominal time of $30 \mathrm{~min}, \mathrm{Hg}^{0}$ never showed a decrease greater than $2.5 \%$ per hour, which was well within the uncertainties of adsorption error $(>5 \%)$. Separate experiments were performed to ensure that there was no depletion of $\mathrm{Hg}^{0}$ after the equilibrium time $(2 \mathrm{~h})$ due to the surface of the wall. Similarly, the rate loss of $\mathrm{O}_{3}\left(k^{\mathrm{O}_{3}}{ }_{\mathrm{ads}}\right)$ was determined to be $(1.9-2.6) \times 10^{-3} \mathrm{~min}^{-1}$ over the concentration range $10-50 \mathrm{ppm}$ at $298 \mathrm{~K}$ in $\mathrm{ca} .0 .4 \mathrm{~cm}^{-1} \mathrm{~s} / \mathrm{v}$ ratio. The decrease in concentration was about $5.6 \%$ over 30 min-period and did not exceed $2 \%$ over the several hours.

The relative rate method is employed in our investigation that involves the measurement of the disappearance of the reactant and reference compounds, according to eqns. (1) and (2).

$$
\begin{array}{r}
\mathrm{O}_{3}+\mathrm{Hg}^{0} \stackrel{k_{\mathrm{Hg}}}{\longrightarrow} \text { products, }-\mathrm{d}\left[\mathrm{Hg}^{0}\right] / \mathrm{d} t=k_{\mathrm{Hg}}\left[\mathrm{O}_{3}\right]\left[\mathrm{Hg}^{0}\right] \\
\mathrm{O}_{3}+\mathrm{Ref} \stackrel{k_{\mathrm{Ref}}}{\longrightarrow} \text { products, } \quad-\mathrm{d}[\mathrm{Ref}] / \mathrm{d} t=k_{\mathrm{Ref}}\left[\mathrm{O}_{3}\right][\mathrm{Ref}]
\end{array}
$$


(C) 2004 the Owner Societies (Royal Society of Chemistry)

https://pubs.rsc.org/en/content/articlelanding/2004/cp/b311150d/unauth

If mercury reacts solely with ozone (i.e., there is no major pathway leading to reformation of reactants or further destruction of reactants), the relationship between the concentration of the reactant and the reference compound is given by,

$$
\ln \left\{\left[\mathrm{Hg}^{0}\right]_{0} /\left[\mathrm{Hg}^{0}\right]_{t}\right\}=k_{\mathrm{Hg}} / k_{\mathrm{Ref}} \ln \left\{[\operatorname{Ref}]_{0} /[\operatorname{Ref}]_{t}\right\}
$$

where $\left[\mathrm{Hg}^{0}\right]_{0}$ and $[\mathrm{Ref}]_{0}$ are the initial concentrations of mercury and reference compounds and $\left[\mathrm{Hg}^{0}\right]_{t}$ and $[\mathrm{Ref}]_{t}$ are the corresponding concentrations at time $t$. Hence, a plot of $\ln \left\{\left[\mathrm{Hg}^{0}\right]_{0} /\left[\mathrm{Hg}^{0}\right]_{t}\right\}$ vs $\ln \left\{[\mathrm{Ref}]_{0} /[\mathrm{Ref}]_{t}\right\}$ will have a slope equal to the ratio of the rate constants, $k_{\mathrm{Hg}} / k_{\mathrm{Ref}}$ with zero intercept. Propene and 1-butene were chosen as the reference compounds in these kinetic investigations. Initial concentrations of the reactants were: 0.5-1.0 ppm $\left(1 \mathrm{ppm}=2.46 \times 10^{13}\right.$ molecules $\mathrm{cm}^{-3}$ at $298 \mathrm{~K}$ and 760 Torr $)$ for $\mathrm{Hg}^{0}, 1-10 \mathrm{ppm}$ for the reference, 10-30 ppm for ozone, and 300-500 ppm for 1,3,5-trimethyl benzene (TMB). TMB was used as the HO radical scavenger in some experiments. The decrease of concentration of both $\mathrm{Hg}^{0}$ and the reference molecules upon addition of ozone were monitored by injecting the reaction samples from the reaction flask into the GC-MS using gas tight syringe at $298 \mathrm{~K}$. In each kinetic run, the typical volume of the sample injected was $200 \mu \mathrm{L}$.

The absolute rate technique of the reaction of $\mathrm{Hg}^{0}$ with ozone was carried out under pseudofirst-order condition with respect to $\mathrm{Hg}^{0}$. The initial concentrations were $0.5-1.0 \mathrm{ppm}$ for $\mathrm{Hg}^{0}$ and 10-50 ppm for $\mathrm{O}_{3}$. The experiments were performed over the temperature range $283-323 \mathrm{~K}$. During the experiment, the evacuated reactor was initially filled with $\mathrm{Hg}$-saturated $\mathrm{N}_{2}$ at 400 Torr, then pressure was brought up to $c a .750$ Torr, and kept for $2 \mathrm{~h}$ for equilibration. The mercury concentration decay was monitored using GC-MS at different ozone concentrations after addition of the requisite volume of ozone. During the reaction, the reactor compartment was kept at constant temperature.

Ozone was produced by an ozone generator (model OL 100/DS, Ozone Services Inc.) by a silent discharge technique. The resulting $\mathrm{O}_{3} / \mathrm{O}_{2}$ mixture was then trapped in a U-tube containing silica gel cooled at $200 \mathrm{~K}$ in a mixture of dry ice-acetone bath. Ozone was transferred to an evacuated source flask by allowing the trap to warm up to ambient temperature and the flask was then brought to 760 Torr pressure by purging the trap with $\mathrm{N}_{2}$. An ultraviolet-visible spectrophotometer (UV-VIS, Varian Cary-50 Bio) was used to monitor the ozone concentration in the source flask. The background ozone decays were monitored periodically at $\lambda=254 \mathrm{~nm}$ using the same UV-VIS spectrophotometer and decays were found to be negligible. Finally, a calculated amount of ozone was transferred from the source flask to the reaction flask using the gas-tight syringe.

2.2 Product studies

Before analysis, the reaction products were collected in three different ways: (i) in a 0.5 micron Teflon filter by using a vacuum system to a residual pressure of $0.5 \mathrm{Torr}$; (ii) in a trap cooled by liquid nitrogen temperature; and (iii) by washing the wall of the reaction chamber with a small volume of solvent. The collected samples were then analyzed by different methods as mentioned below.

Direct probe. Pre-concentrated volatile products were collected by a flow of gas from a reaction flask through a $1.1 \mathrm{~mm}$ id $\times 10 \mathrm{~cm}$ length Pyrex tube, which was inserted in liquid $\mathrm{N}_{2}$. Condensed products from the Pyrex tube were evaporated at stepwise elevated temperature to the chemical ionization ion source of a Kratos MS25RFA mass spectrometer using a direct probe. 
(C) 2004 the Owner Societies (Royal Society of Chemistry)

https://pubs.rsc.org/en/content/articlelanding/2004/cp/b311150d/unauth

ICP-MS. Before study, samples were prepared by washing the wall of the reaction flask and Teflon filters with a mixture of $20 \mathrm{ml}$ of $40 \% \mathrm{HNO}_{3}$ and $0.5 \mathrm{ml}$ of $30 \% \mathrm{H}_{2} \mathrm{O}_{2}$, and then diluted to $100 \mathrm{ml}$. The diluted sample was heated to $350 \mathrm{~K}$ for $20 \mathrm{~min}$ to decompose $\mathrm{H}_{2} \mathrm{O}_{2}$, and analyzed by ICP-MS. Derivatization. This method is based on the qualitative conversion of $\mathrm{HgO}$ to $\mathrm{HgCl}_{2}$, followed by the transformation of volatile organomercury compound, $n-\mathrm{Bu}_{2} \mathrm{Hg}$. Initially, the wall of the reaction flask and the trap were treated with $20 \mathrm{ml}$ of conc. $\mathrm{HCl}$, which transformed $\mathrm{HgO}$ to $\mathrm{HgCl}_{2}$. The sample was then evaporated to dryness for complete removal of $\mathrm{HCl}$, which resulted in the formation of white residue. Finally, the derivatization was performed according to the method mentioned earlier. $\frac{35.36}{2} \mathrm{ml}$ of toluene and $0.4 \mathrm{ml}$ of $2 \mathrm{M}$ n-butylmagnesiumchloride in tetrahydrofuran were added to the white residue. The mixture was then centrifuged at $273 \mathrm{~K}$ for $10 \mathrm{~min}$ by keeping it in a $10 \mathrm{ml}$ centrifuge tube with occasional shaking. Subsequently, $0.4 \mathrm{ml}$ of $0.6 \mathrm{M} \mathrm{HCl}$ was added to quench the excess derivatizing agent. The mixture was centrifuged once again and the organic phase was collected for analysis in GC-MS.

$$
\begin{gathered}
\mathrm{HgO}+2 \mathrm{HCl} \rightarrow \mathrm{HgCl}_{2}+\mathrm{H}_{2} \mathrm{O} \\
\mathrm{HgCl}_{2}+2 n-\mathrm{BuMgCl} \rightarrow n-\mathrm{Bu}_{2} \mathrm{Hg}+2 \mathrm{MgCl}_{2}
\end{gathered}
$$

\subsection{Materials}

Mercury (99.99\% purity), propene (>99\%), 1-butene (>99\%), trimethylbenzene $(98 \%)$, and $n$ butyl magnesium chloride (2 $\mathrm{M}$ solution in tetrahydrofuran) were supplied by Aldrich. Toluene (99.9\%), hydrogen peroxide (30\%), hydrochloric acid (Trace Metal grade), and nitric acid (Trace Metal grade) were purchased from Fisher. All the compounds were used without further purification. The UHP nitrogen, extra dry oxygen (99.96\%), and helium were obtained from Matheson.

\section{Results and discussion}

\subsection{Relative rate technique}

Kinetics. The relative rate technique relies on the assumption that the reactants are removed solely by the reaction with $\mathrm{O}_{3}$. This may not be the case if an alkene is the reference compound. Evidence ${ }^{37}$ has been provided that significant amount of $\mathrm{HO}$ and $\mathrm{HO}_{2}$ radicals are produced in the gas phase reaction of ozone and alkenes according to the scheme (reaction 6; R represents alkyl group):

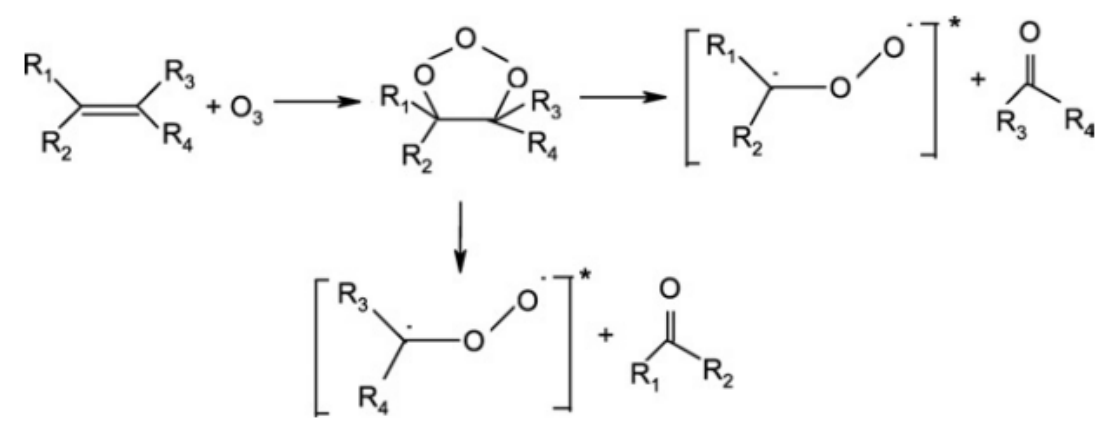

If $\mathrm{R}_{3}=-\mathrm{CH}_{3}$ and $\mathrm{R}_{4}=-\mathrm{H}$, then: 
(C) 2004 the Owner Societies (Royal Society of Chemistry)

https://pubs.rsc.org/en/content/articlelanding/2004/cp/b311150d/unauth

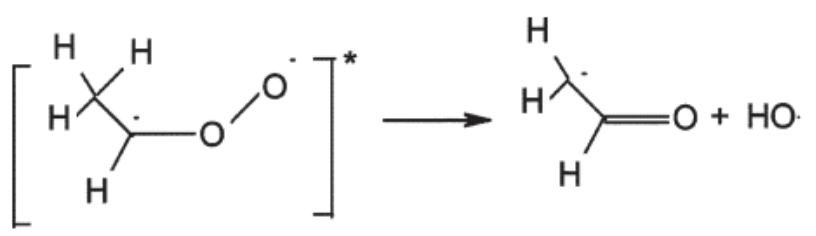
${ }_{40}^{\mathrm{HO}}$ radicals further add to the double bond of the alkene producing alkyl radicals ( $\underline{\text { reaction } 8)} . \underline{37.38-}$

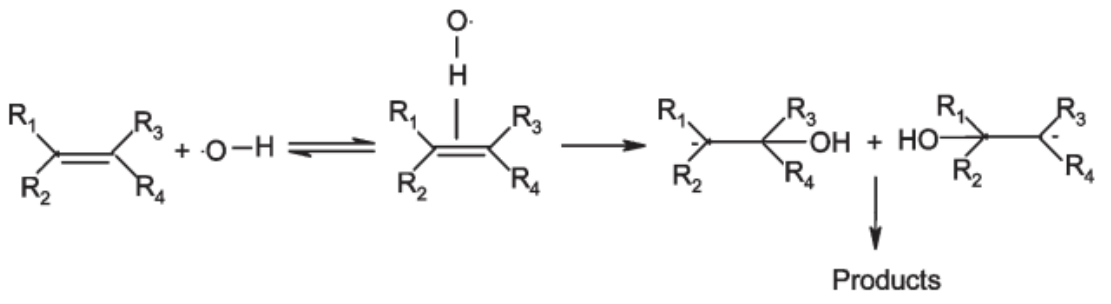

Subsequently, an alkyl radical reacts with oxygen to form a peroxy $\left(\mathrm{RO}_{2}\right)$ radical, which undergoes several potential reaction pathways including formation of the corresponding carbonyl species along with organic free radicals.

Table 1 summarizes the literature rate constant values for the references with $\mathrm{O}_{3}$ and $\mathrm{HO}$ radical. The rate constant of $\mathrm{HO}$ radical initiated oxidation of elemental mercury has been measured to be $8.7 \times 10^{-14} \mathrm{~cm}^{3}$ molecule $\mathrm{e}^{-1} \mathrm{~s}^{-1}$, 5 suggesting a potential significant impact of $\mathrm{HO}$ radicals at $298 \mathrm{~K}$. It is thus important to select experimental conditions to prevent $\mathrm{HO}^{\circ}$ from reacting with reference alkene molecules and $\mathrm{Hg}^{0}$. We hence performed our experiments in the presence of a substantial amount of TMB that scavenges HO radicals generated in this system. The rate constants for the reaction of $\mathrm{HO}^{*}$ with $\mathrm{TMB}$ is high enough $(k=5.75 \times$ $10^{-11} \mathrm{~cm}^{3}$ molecule $\left.{ }^{-1} \mathrm{~s}^{-1}\right)^{44}$ to scavenge a significant fraction of the $\mathrm{HO}$ radical formed in the ozonolysis reaction in contrast to the reaction of TMB with ozone $\left(k=5.0 \times 10^{-19}\right.$ to $2.9 \times$ $10^{-21} \mathrm{~cm}^{3}$ molecule $\left.\mathrm{s}^{-1}\right) .37 .44$ As depicted in Fig. 1, the plot of the relative loss of $\mathrm{Hg}^{0}$ and reference compounds upon reaction in the presence of TMB led to a straight line with near zero intercepts. The data on relative rate constants $k_{\mathrm{Hg}} / k_{\text {Ref }}$ and absolute rate constants, $k_{\mathrm{Hg}}$ at $298 \mathrm{~K}$ are presented in Table 2, suggesting the independency of the relative rate constant on reaction conditions in the presence of TMB. The rate constant data in the presence of TMB are in good agreement within uncertainty limits, with the value of $(7.5 \pm 0.9$ (uncertainty represents accumulative errors) $) \times$ $10^{-19} \mathrm{~cm}^{3}$ molecule ${ }^{-1} \mathrm{~s}^{-1}$ at $298 \mathrm{~K}$ obtained in this study by using the absolute method (section 3.2). Reaction of $\mathrm{O}_{3}$ with atomic $\mathrm{Hg}$ using propene as a reference in Fig. 2 shows noticeable enhancement of the reaction rate in absence of $\mathrm{HO}$ radical scavenger. The effect is more pronounced at higher reference concentration, indicating the secondary reaction caused by the involvement of HO radical during reaction in the absence of TMB. Similar behavior was attributed in our previous studies on the reaction of atomic halogens with elemental mercury. $\underline{\underline{23}}$ 
(C) 2004 the Owner Societies (Royal Society of Chemistry)

https://pubs.rsc.org/en/content/articlelanding/2004/cp/b311150d/unauth
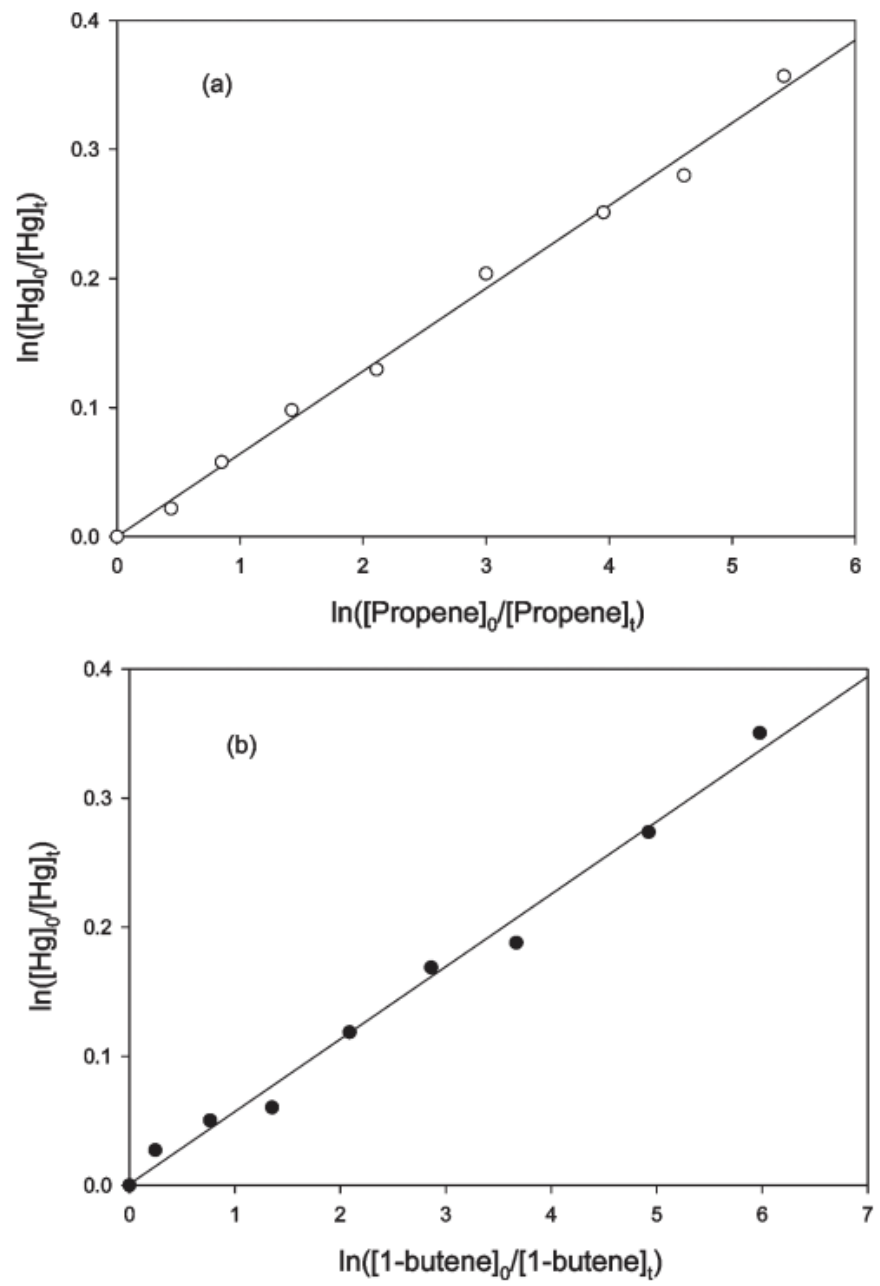

Fig. 1 Relative rate data for $\mathrm{Hg}^{0}-\mathrm{O}_{3}$ reaction at $298 \mathrm{~K}$ using (a) propene and (b) 1-butene as reference in presence of TMB. Initial concentration of TMB was $500 \mathrm{ppm}$. 
(C) 2004 the Owner Societies (Royal Society of Chemistry)

https://pubs.rsc.org/en/content/articlelanding/2004/cp/b311150d/unauth

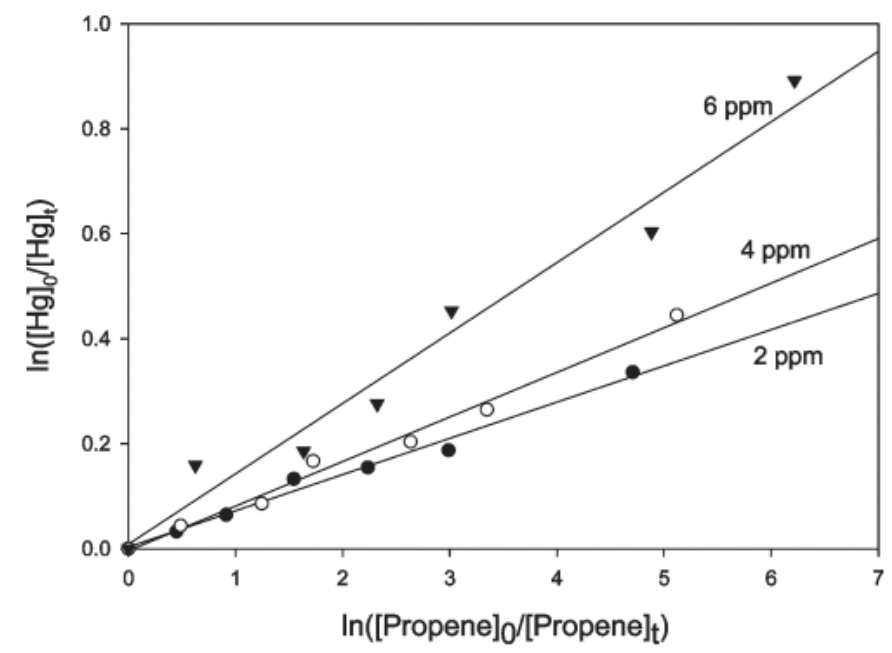

Fig. 2 Typical relative rate plot of $\mathrm{O}_{3}$-initiated reaction of $\mathrm{Hg}^{0}$ using propene as a reference, at $298 \mathrm{~K} .\left[\mathrm{Hg}^{0}\right]=0.5-1.0 \mathrm{ppm}$.

Table 1 Literature rate constant values for mercury, the references and scavenger used in this study with $\mathrm{O}_{3}$ and the hydroxyl radical, along with our results at $298 \mathrm{~K}$

\begin{tabular}{lll}
\hline Substrate & $\begin{array}{l}10^{18} k_{\mathrm{O} 3} / \mathrm{cm}^{3} \\
\text { molecule }\end{array}$ & $\begin{array}{l}10^{11} k_{\mathrm{HO}} / \mathrm{cm}^{3} \\
\text { molecule }\end{array}$ \\
\hline Propene & $11 . \mathrm{s}^{-1}$ & \\
1-Butene & $12.3^{43}$ & $2.63^{42}$ \\
TMB & $0.5^{37}$ & $3.14^{42}$ \\
& $2.9 \times 10^{-3} 4$ & $5.75^{44}$ \\
$\mathrm{Hg}$ & $3.0 \times 10^{-3 a}$ & \\
& $4.90^{a}{ }^{24}$ & $8.7 \times 10^{-3445}$ \\
& $0.42^{a}$ & \\
& $0.75^{b}$ &
\end{tabular}

${ }^{a}$ At $293 \mathrm{~K},{ }^{b}$ values from the present work. 
(C) 2004 the Owner Societies (Royal Society of Chemistry)

https://pubs.rsc.org/en/content/articlelanding/2004/cp/b311150d/unauth

Table 2 Relative rate constants and the corresponding absolute value for the reaction of mercury and ozone using different references at $298 \mathrm{~K}$ in $\mathrm{N}_{2} \cdot\left[\mathrm{Hg}^{0}\right]=0.5-1.0 \mathrm{ppm}^{b}$

\begin{tabular}{lccc}
\hline Reference & {$[\mathrm{Ref}] / \mathrm{ppm}$} & $k_{\mathrm{Hg}} / k_{\mathrm{Ref}}$ & $\begin{array}{l}10^{19} k_{\mathrm{Hg}+\mathrm{O} 3} / \mathrm{cm}^{3} \\
\mathrm{molecule}^{-1} \mathrm{~s}^{-1}\end{array}$ \\
\hline Propene & 10.0 & $0.064 \pm 0.002$ & $7.05 \pm 0.22^{a}$ \\
1-butene & 10.0 & $0.056 \pm 0.002$ & $6.91 \pm 0.25^{a}$ \\
Propene & 2.0 & $0.069 \pm 0.004$ & $7.59 \pm 0.44$ \\
Propene & 4.0 & $0.085 \pm 0.004$ & $9.35 \pm 0.44$ \\
Propene & 6.0 & $0.134 \pm 0.01$ & $14.8 \pm 1.13$ \\
${ }^{a}$ In the presence of $500 \mathrm{ppm} \mathrm{TMB.}^{b}$ Errors represent $\pm 2 \sigma$ of linear \\
regression plots. \\
\hline
\end{tabular}

\subsection{Absolute rate technique}

Kinetics. The addition of $\mathrm{O}_{3}$ to the reaction flask increases the heterogeneous loss of $\mathrm{Hg}^{0}$ on the flask walls, as preliminary pseudo-first-order decays of $\mathrm{Hg}^{0}$ were nonlinear. This may be due to the reversible adsorption of $\mathrm{Hg}^{0}$ on the wall of the reaction flask. This surface catalyzed reaction has also been observed previously for the reaction of $\mathrm{Hg}^{0}$ with ozone..$^{30} \mathrm{In}$ order to decrease the wall loss of the compounds, the wall of the reaction flask was coated with halocarbon wax. In addition, to minimize the effect of adsorption on the reaction kinetics, the reaction mixture was usually kept for at least $2 \mathrm{~h}$ for equilibration before injecting ozone into the reaction flask.

Pseudo-first-order rate constants at $298 \mathrm{~K}$ for the $\mathrm{Hg}^{0}-\mathrm{O}_{3}$ reaction were obtained from the logarithmic plots of the variation of Hg-signal versus time and are presented in Table 3 . Fig. $\underline{3}$ depicts a series of typical pseudo-first-order decays of the measured $\mathrm{Hg}$ signal versus reaction distance at different initial concentrations of $\mathrm{O}_{3}$, which suggests that the rate of consumption of $\mathrm{Hg}^{0}$ increases with increasing $\mathrm{O}_{3}$ concentrations. Two kinetic regimes that appear in Fig. 3 reveal (i) that the linear plots corresponding to the first regime are due to simple gas phase reaction; and (ii) second kinetic regime due to surface enhancement reactions in addition to the gas phase reaction. The dependence of the pseudo-first-order reaction on the initial concentration of ozone at $298 \mathrm{~K}$ is shown in Fig. 4 from the linear plot of kversus $\mathrm{O}_{3}$ concentration. The effective bimolecular rate constants at $298 \mathrm{~K}$ were calculated from a linear plot of kversus $\mathrm{O}_{3}$ concentration in Fig. 4 and determined to be $(7.49 \pm 0.04) \times 10^{-19} \mathrm{~cm}^{3}$ molecule ${ }^{-1} \mathrm{~s}^{-1}( \pm 2 \sigma)$. If we include accumulative errors, the reported rate constant would be $(7.5 \pm 0.9) \times 10^{-19} \mathrm{~cm}^{3}$ molecule $\mathrm{e}^{-1} \mathrm{~s}^{-1}$ for the first part of the kinetic curve. Values of $(9.16 \pm 0.06) \times 10^{-19} \mathrm{~cm}^{3}$ molecule $\mathrm{s}^{-1} \mathrm{~s}^{-1}(2 \sigma)$ for the second part of the kinetic curve were obtained. 
(C) 2004 the Owner Societies (Royal Society of Chemistry)

https://pubs.rsc.org/en/content/articlelanding/2004/cp/b311150d/unauth

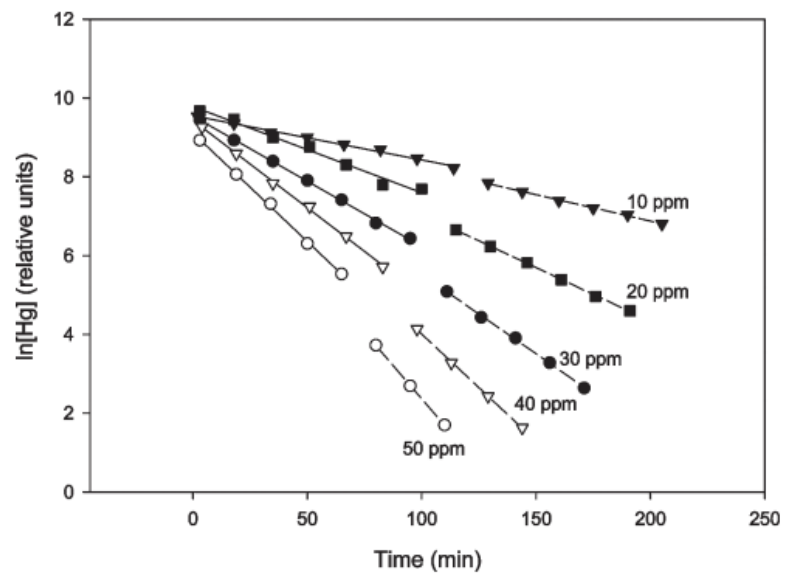

Fig. 3 Pseudo-first-order plots of change of mercury signal over time at different initial concentrations of $\mathrm{O}_{3}$. Reactions were carried out in a 2-L flask coated with halocarbon wax.

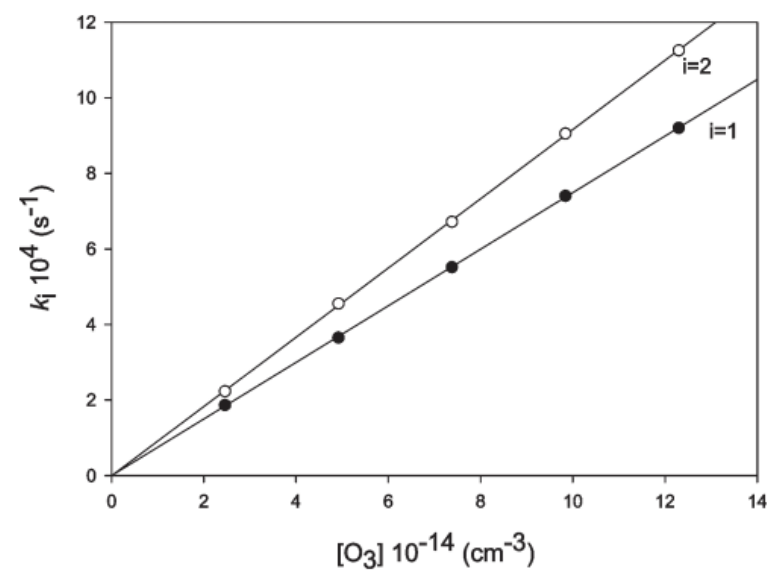

Fig. 4 Dependence of the pseudo-first-order rate constant on the initial concentrations of $\mathrm{O}_{3}(10-50 \mathrm{ppm})$ at $298 \mathrm{~K}$ for the first $(i=1)$ and second $(i=2)$ parts of the kinetic curve.

Table 3 Absolute rate constants for the reaction of $\mathrm{Hg}^{0}+\mathrm{O}_{3}$ at $298 \mathrm{~K}$ in $\mathrm{N}_{2}$. Walls were treated with halocarbon wax and $\left[\mathrm{Hg}^{0}\right]$ was $0.5-1.0 \mathrm{ppm}^{a}$

\begin{tabular}{|c|c|c|c|c|c|}
\hline \multirow[b]{2}{*}{$V_{\text {cell }} / \mathrm{L}$} & \multirow[b]{2}{*}[\mathrm{O}_{3}]{$/ \mathrm{ppm}$} & \multicolumn{2}{|l|}{$k_{i}$} & \multicolumn{2}{|l|}{$k_{i i}$} \\
\hline & & $/ 10^{-4} \mathrm{~s}^{-1}$ & $/ 10^{-19} \mathrm{~cm}^{3}$ molecule $\mathrm{s}^{-1} \mathrm{~s}^{-1}$ & $/ 10^{-4} \mathrm{~s}^{-1}$ & $/ 10^{-19} \mathrm{~cm}^{3}$ molecule ${ }^{-1} \mathrm{~s}^{-1}$ \\
\hline 2.0 & 10 & $1.86 \pm 0.06$ & $7.59 \pm 0.26$ & $2.23 \pm 0.04$ & $9.08 \pm 0.18$ \\
\hline 2.0 & 20 & $3.65 \pm 0.19$ & $7.42 \pm 0.41$ & $4.55 \pm 0.05$ & $9.25 \pm 0.09$ \\
\hline 2.0 & 30 & $5.52 \pm 0.08$ & $7.47 \pm 0.11$ & $6.72 \pm 0.13$ & $9.10 \pm 0.17$ \\
\hline 2.0 & 40 & $7.40 \pm 0.12$ & $7.52 \pm 0.13$ & $9.05 \pm 0.10$ & $9.19 \pm 0.11$ \\
\hline 2.0 & 50 & $9.20 \pm 0.19$ & $7.48 \pm 0.15$ & $11.2 \pm 0.12$ & $9.15 \pm 0.10$ \\
\hline 0.14 & 40 & $7.28 \pm 0.36$ & $7.40 \pm 0.37$ & $11.6 \pm 0.31$ & $11.75 \pm 0.32$ \\
\hline 3.0 & 40 & $7.41 \pm 0.10$ & $7.53 \pm 0.11$ & $8.75 \pm 0.30$ & $8.89 \pm 0.31$ \\
\hline 5.0 & 40 & $7.38 \pm 0.04$ & $7.50 \pm 0.05$ & $8.60 \pm 0.08$ & $8.73 \pm 0.08$ \\
\hline
\end{tabular}


(C) 2004 the Owner Societies (Royal Society of Chemistry)

https://pubs.rsc.org/en/content/articlelanding/2004/cp/b311150d/unauth

Our room temperature $(298 \mathrm{~K})$ results are in the same order of magnitude as the results of Slemr et al. $2\left(4.2 \times 10^{-19} \mathrm{~cm}^{3}\right.$ molecule $\mathrm{e}^{-1} \mathrm{~s}^{-1}$ at $\left.293 \mathrm{~K}\right)$ within experimental uncertainties, and closer to this value than to any others previously reported. Our results are slightly lower than estimations by Schroeder et al. $\underline{.4}\left(4.9 \times 10^{-18} \mathrm{~cm}^{3}\right.$ molecule $\mathrm{e}^{-1} \mathrm{~s}^{-1}$ at $\left.293 \mathrm{~K}\right)$ and Iverfeldt $e t$ al. $.11 .7 \times 10^{-18} \mathrm{~cm}^{3}$ molecule $\mathrm{s}^{-1}$ at $293 \mathrm{~K}$ and $71 \%$ relative humidity). However, our value is higher than the reported value of $(3.0 \pm 2) \times 10^{-20} \mathrm{~cm}^{3}$ molecule ${ }^{-1} \mathrm{~s}^{-1}$ (at $293 \mathrm{~K}$ ) by Hall..$^{30}$

The effect of surface-to-volume ratio (s/v)

To decrease the significance of surface reactions, it is common practice in this laboratory to coat the reaction vessels using several coating reagents, including halocarbon wax as used in this study.. ${ }^{23}$ The effect of increased surface-to-volume ratio $(\mathrm{s} / \mathrm{v})$ was observed by performing the reaction in 0.14-, 2-, 3-, and 5-L Pyrex flask with s/v ratios of 0.932, 0.383, 0.335, and $0.282 \mathrm{~cm}^{-1}$, respectively. The rate constants were measured for both kinetic regimes at different $\mathrm{s} / \mathrm{v}$ ratios and are presented in Table 3. We observed that the rate constants obtained for the first kinetic regime at different s/v ratios are almost identical within experimental uncertainties. However, there is a significant increase in the rate constants for the second part of the kinetic reaction with increasing $\mathrm{s} / \mathrm{v}$ ratios (Fig. 5), which suggests a secondary reaction arising from surface catalysis. From extrapolation to zero s/v ratios (Fig. 5), we obtained the gas phase rate constant of $(7.38 \pm 0.05)$ $\times 10^{-19} \mathrm{~cm}^{3}$ molecule $\mathrm{s}^{-1}( \pm 2 \sigma)$ for the $\mathrm{Hg}^{0}+\mathrm{O}_{3}$ reaction. This value is close (within experimental uncertainties) to the value of $(7.49 \pm 0.04) \times 10^{-19} \mathrm{~cm}^{3}$ molecule ${ }^{-1} \mathrm{~s}^{-1}( \pm 2 \sigma)$ obtained from our absolute studies. The former value is very similar to the values obtained using both absolute and relative techniques. Since in the relative technique, the uncertainties on the absolute rate constant of the reference molecules or secondary reactions due to the presence of the reference compound lead to additional errors, we herein choose kinetic results obtained by absolute method as a more accurate value. We thus report the value of $(7.5 \pm 0.9$ (accumulated errors) $) \times$ $10^{-19} \mathrm{~cm}^{3}$ molecule ${ }^{-1} \mathrm{~s}^{-1}$ as a reliable reaction rate constant for $\mathrm{O}_{3}$-initiated oxidation of elemental mercury.

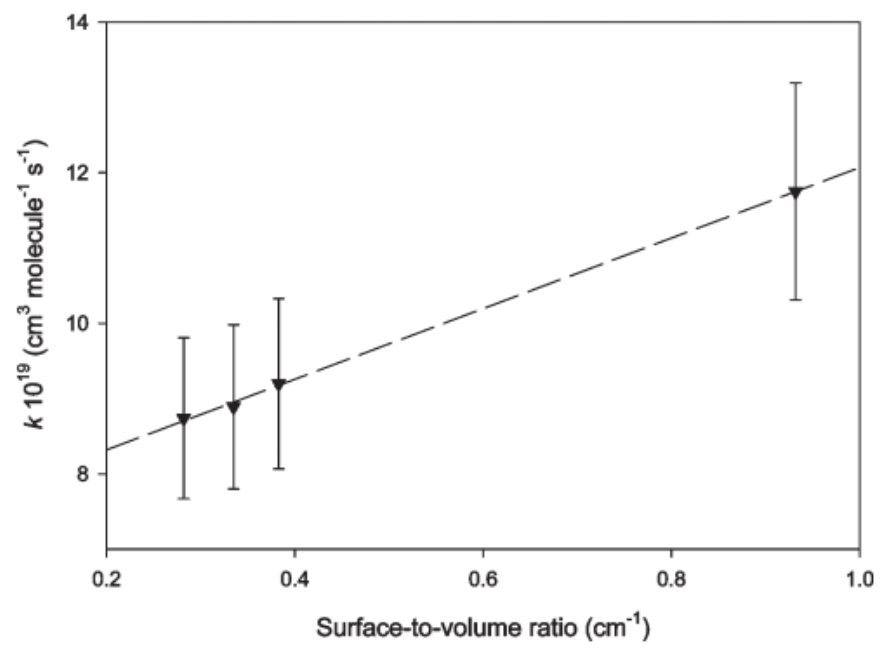

Fig. 5 The effect of variation of surface-to-volume ratio. Error bars depict accumulated errors.

Temperature dependence study. The temperature dependence of the reaction of $\mathrm{O}_{3}$ with $\mathrm{Hg}^{0} \mathrm{was}$ investigated over the temperature range $283-323 \mathrm{~K}$ at near atmospheric pressure. The observed 
(C) 2004 the Owner Societies (Royal Society of Chemistry)

https://pubs.rsc.org/en/content/articlelanding/2004/cp/b311150d/unauth

absolute rate constants at 283, 298, 313, and $323 \mathrm{~K}$ are presented in Table 4. The Arrhenius plot of this data is shown in Fig. 6. The activation energy $\left(E_{\mathrm{A}}\right)$ and pre-exponential factor $(A)$ were determined to be $11.7 \pm 0.27 \mathrm{~kJ} \mathrm{~mol}^{-1}( \pm 2 \sigma)$ and $8.43 \times 10^{-17} \mathrm{~cm}^{3}$ molecule ${ }^{-1} \mathrm{~s}^{-1}$, respectively. The calculated activation energy for this reaction is slightly lower than those estimated theoretically by Yarwood et al. (44 $\left.\mathrm{kJ} \mathrm{mol}^{-1}\right) .{ }^{46}$ However, there is a good agreement of the value of the activation energy with our study and the estimated value obtained experimentally by Hall (10 $\left.\mathrm{kJ} \mathrm{mol}^{-1}\right) \cdot \underline{30}$

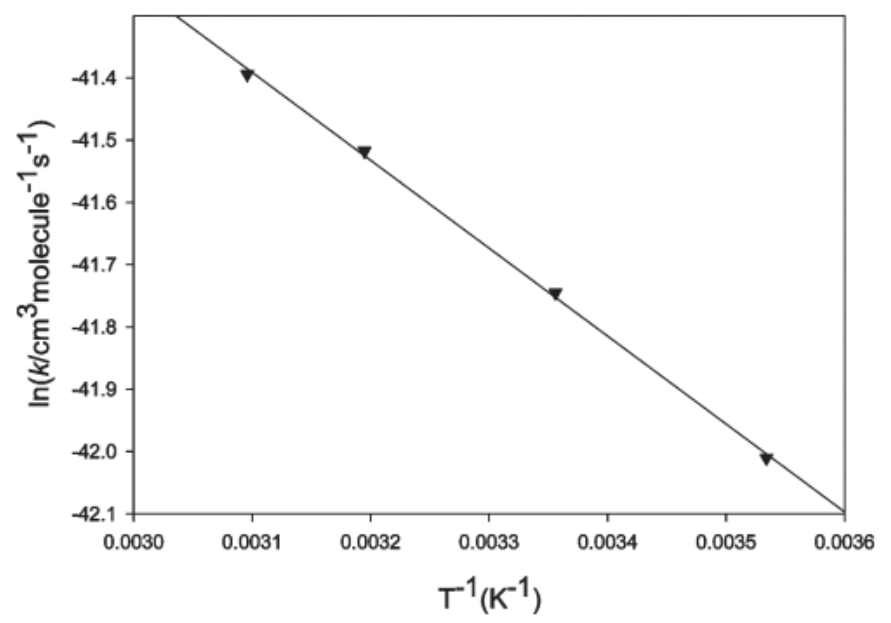

Fig. 6 Arrhenius plot for the reactions of $\mathrm{Hg}^{0}$ and $\mathrm{O}_{3}$ over the temperature range $283-323 \mathrm{~K}$.

Table 4 Temperature dependence of rate constants for the reaction of $\mathrm{Hg}^{0}$ and $\mathrm{O}_{3}$ in the gas phase. $\left[\mathrm{Hg}^{0}\right]=0.5-1.0 \mathrm{ppm},\left[\mathrm{O}_{3}\right]=20 \mathrm{ppm}^{a}$

\begin{tabular}{lc}
\hline Temperature $/ \mathrm{K}$ & $10^{19} \mathrm{k} / \mathrm{cm}^{3}$ molecule ${ }^{-1} \mathrm{~s}^{-1 b}$ \\
\hline 283 & $5.69 \pm 0.15$ \\
298 & $7.42 \pm 0.41$ \\
313 & $9.32 \pm 0.19$ \\
323 & $10.5 \pm 0.65$ \\
${ }^{a}$ Errors represent $\pm 2 \sigma$ of linear regression plots. ${ }^{b}$ In this study the \\
calculated activation energy $\left(E_{\mathrm{A}}\right)$ and pre-exponential $(A)$ factor were \\
found to be $11.7 \pm 0.27 \mathrm{~kJ} \mathrm{~mole}^{-1}$, and $8.43 \times 10^{-17} \mathrm{~cm}^{3}$ molecule ${ }^{-1}$ \\
$\mathrm{~s}^{-1}$, respectively. \\
\hline
\end{tabular}

\subsection{Product studies}

The reaction of $\mathrm{Hg}^{0}$ with $\mathrm{O}_{3}$ may proceed 30 either according to eqns. (9) or (10), where reaction $\underline{(9)}$ is a simple bimolecular gas phase reaction and reaction (10) has a complex nature.

$$
\mathrm{Hg}^{0}(\mathrm{~g})+\mathrm{O}_{3}(\mathrm{~g}) \rightarrow \mathrm{HgO}(\mathrm{g})+\mathrm{O}_{2}(\mathrm{~g}) \quad \Delta G_{298}^{0}=-171 \mathrm{~kJ} \mathrm{~mol}^{-1}
$$


(C) 2004 the Owner Societies (Royal Society of Chemistry)

https://pubs.rsc.org/en/content/articlelanding/2004/cp/b311150d/unauth

$$
\mathrm{Hg}^{0}(\mathrm{~g})+\mathrm{O}_{3}(\mathrm{~g}) \rightarrow \mathrm{HgO}(\mathrm{s})+\mathrm{O}_{2}(\mathrm{~g}) \quad \Delta G_{298}^{0}=-254 \mathrm{~kJ} \mathrm{~mol}^{-1}
$$

The large negative Gibbs free energy indicates significant conversion of $\mathrm{Hg}^{0}$ to $\mathrm{HgO}$. All previous literatures on $\mathrm{O}_{3}$-initiated reaction of mercury have suggested $\mathrm{HgO}$ as the only reaction product, but this product has never been identified experimentally until the present study. Existence of mercuric oxide, $\mathrm{HgO}$, was determined in the gas phase from the suspended aerosols and on the wall of the reaction flask, and are mentioned in the following paragraphs.

Mercury oxide, $\mathrm{HgO}$, is a well known compound, but the gas phase species could not be identified in this study by syringe sampling into the GC-MS due to the low vapor pressure at room temperature and lower sensitivity of the $\mathrm{MS}$ instrument to $\mathrm{HgO}$ in comparison to $\mathrm{Hg}^{0}$. Existence of $\mathrm{HgO}$, as being formed in the decomposition of $\mathrm{O}_{3}$ by $\mathrm{Hg}^{0}$, was observed in these investigations by different methods described below.

After completion of the reaction, the reaction flask was heated to $363 \mathrm{~K}$ and then connected through a small tube, which was inserted in liquid $\mathrm{N}_{2}$. Subsequently, volatile products were collected in that tube by slowly passing the gas mixture using the vacuum system, and the tube was sealed at both ends. Condensed products inside the tube were analyzed at stepwise elevated temperature to the electron-impact ion source of the MS instrument using the direct probe. However, this method was not successful due to the decomposition of $\mathrm{HgO}$, which may be attributed to the high-energy content of the electron-impact ion source. Chemical ionization ion $\underline{\text { source, }}$, where $\underline{\mathrm{NH}_{3}}$ was the reagent gas, was thereafter chosen to perform further investigations. The tube, containing the volatile reaction product, was placed in the direct probe of the MS instrument and heated stepwise to $350 \mathrm{~K}$. Fig. 7a represents the mass spectra of $\mathrm{HgOH}^{+}$, which was obtained by the combination of $\mathrm{HgO}$ and $\mathrm{H}^{+}\left(\mathrm{NH}_{3}\right.$ being the source of $\left.\mathrm{H}^{+}\right)$. Fig. $7 \mathrm{~b}$ corresponds to the mass spectra of $\mathrm{HgO}$ based on theoretical calculations. The observed numerical $\mathrm{m} / \mathrm{z}$ values in Fig. 7a include the $\mathrm{m} / \mathrm{z}$ values of $\mathrm{HgO}$ incremented by one, which originated from the $\mathrm{H}^{+}$ions. Formation of $\mathrm{HgO}$ is also confirmed by analyzing the derivatized sample using GC-MS (Fig. 8). Note that elemental mercury was not considered in derivatization analysis. 

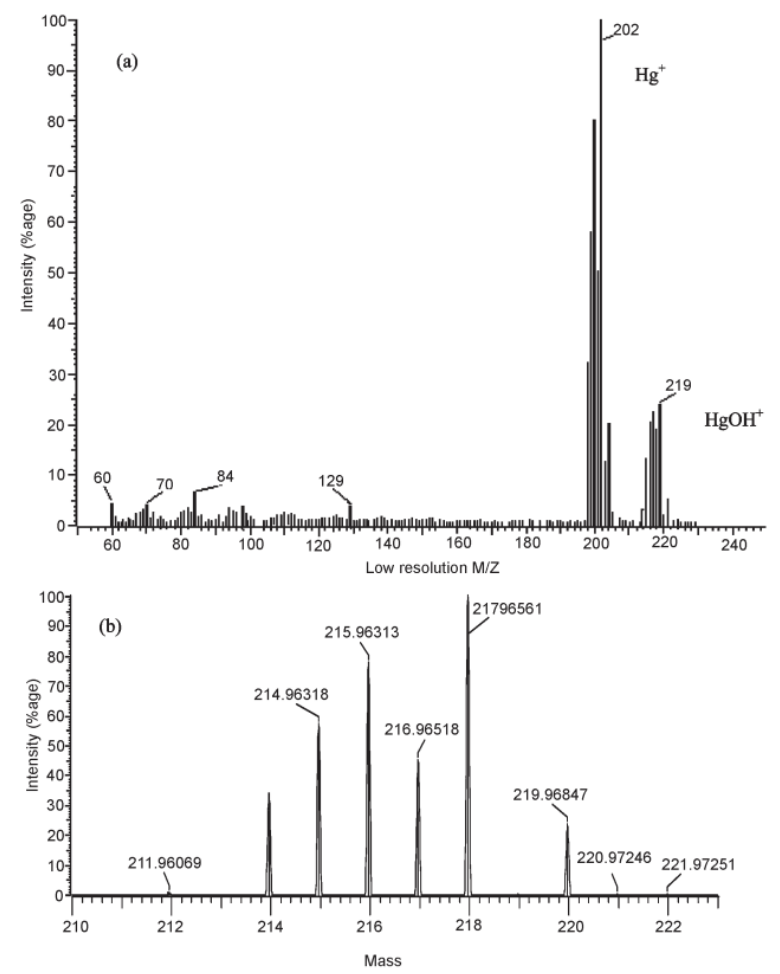

Fig. 7 Mass spectra of volatile product formed in the reaction of $\mathrm{Hg}^{0}$ and $\mathrm{O}_{3}$ (a) experimental and (b) theoretical calculation based on $\mathrm{HgO}$.

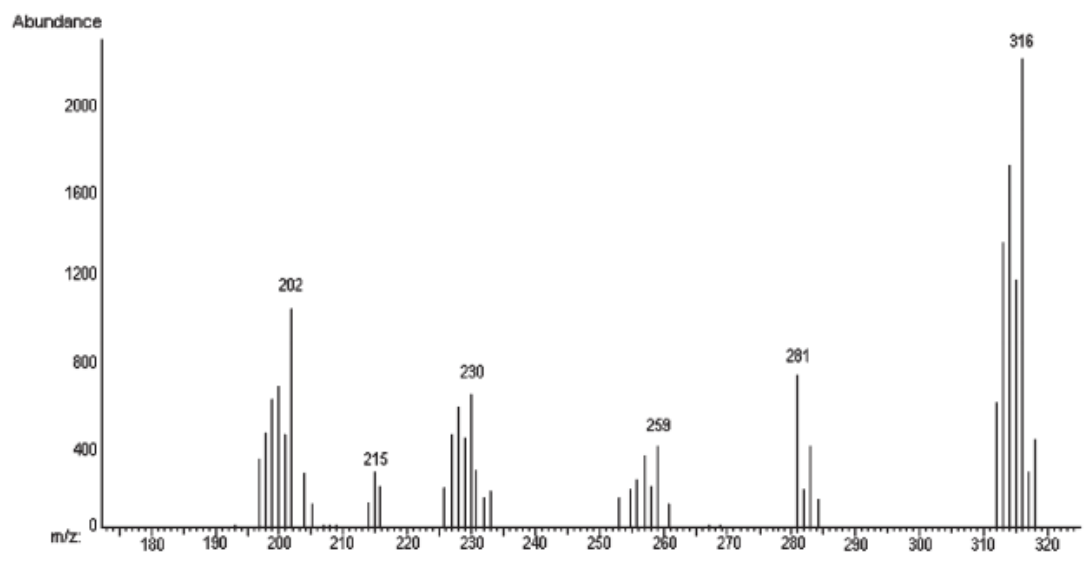

Fig. 8 Mass spectra of the derivatized inorganic mercury (di- $n$-butylmercury) indicating the presence of $\mathrm{HgO}$.

In order to determine the amount of the oxidized product in different parts of the reaction chamber, we performed several ICP-MS studies. In the first part, the reaction flask was evacuated through a 0.5 micron Teflon filter to a residual pressure of 0.5 Torr. Hence, the collected samples represent only aerosols with sizes greater than 0.5 microns. The filter was washed with a $\mathrm{HNO}_{3} / \mathrm{H}_{2} \mathrm{O}_{2}$ mixture and then analyzed with ICP-MS. The analysis report indicated that $0.7 \%$ of mercury was converted to the oxidized product in the aerosol mixture in comparison to the amount of mercury filled in the reaction flask before the reaction, which reflects the insignificant contribution of aerosol to the reaction products. In the second part, the reaction products were 
(C) 2004 the Owner Societies (Royal Society of Chemistry)

https://pubs.rsc.org/en/content/articlelanding/2004/cp/b311150d/unauth

trapped in a cooled coiled Pyrex trap, treated with $\mathrm{HNO}_{3} / \mathrm{H}_{2} \mathrm{O}_{2}$ mixture, and analyzed with ICPMS. The analysis recovered between $9-13 \%$ of the mercury in the gas-aerosol phase. In the last part, reaction products were collected from the wall of the reaction flask for ICP-MS analysis by washing the wall with $\mathrm{HNO}_{3} / \mathrm{H}_{2} \mathrm{O}_{2}$ mixture. Under our experimental conditions, recovery of $\mathrm{Hg}$ from the wall was $83-90 \%$. We also investigated the adsorption of $\mathrm{Hg}^{0}$ on halocarbon wax coating and observed to be about $4( \pm 2) \%$. Henceforth, the quantitative yield of $\mathrm{Hg}^{2+}$ in the wall is the difference of $4( \pm 2) \%$ from (83-90)\%, i.e. (79-86\%) $\pm 2 \%$, which implied that most of the reaction products were deposited on the reaction flask walls.

\section{Atmospheric implications}

The ozone initiated reactions seem to be too slow to describe rapid tropospheric mercury depletion events in several locations in the high-Arctic, Antarctic, and sub-Arctic. However, the deposition of the major product of $\mathrm{Hg}^{0}+\mathrm{O}_{3}$ reactions, $\mathrm{HgO}$, to environmental surface, followed by the biomethylation and enrichment of highly toxic methyl mercury in the aquatic food chain, can be an issue of environmental concern. 47 The contribution of $\mathrm{O}_{3}$-initiated mercury depletion to the chemistry of the troposphere particularly during dark seasons, as photolytic sources of generation of radicals are decreased, can be of great importance.

\section{Concluding remarks}

In summary, kinetic study of the gas phase reaction of elemental mercury with ozone have been performed extensively at temperature range of 283-323 $\mathrm{K}$ in $\mathrm{N}_{2}$ under near atmospheric pressure using two different experimental techniques (relative and absolute). Our reported room temperature value of $(7.5 \pm 0.9) \times 10^{-19} \mathrm{~cm}^{3}$ molecule ${ }^{-1} \mathrm{~s}^{-1}$ seemingly is a reliable rate constant for $\mathrm{Hg}^{0}+\mathrm{O}_{3}$ reaction and has consistently obtained from both relative and absolute studies and at various surface-to-volume ratios of the reaction vessels. For the first time, the reaction product, $\mathrm{HgO}$, was determined in the gas phase from the suspended aerosols, and on the walls of the reaction chamber. Under a typical continental, mid-latitude and ambient setting of ozone mixing ratios of $20 \mathrm{ppbv}$, we can calculate the tropospheric mercury lifetime upon $\mathrm{O}_{3}$-initiated reactions to be $c a$. 32 days, long enough for long range transport, as observed in the mercury measurements. $\mathrm{Hg}+$ $\mathrm{O}_{3}$ reactions should thus be incorporated in atmospheric and biogeochemical models aimed at understanding of biogeochemical cycling of mercury.

\section{Acknowledgements}

We cordially thank the Natural Science and Engineering Research Council of Canada (NSERC), the Fond pour la Formation de Chercheurs et l'Aide a la Recherche (FCAR), the Canadian Foundation for Innovation (CFI), the COMERN project, and Environment Canada for financial support, as well as Clare Salustro for proofreading this manuscript.

\section{References}

1. W. Seiler, C. Eberling and F. Slemr, Pageoph, 1980, 118, 963. 
(C) 2004 the Owner Societies (Royal Society of Chemistry)

https://pubs.rsc.org/en/content/articlelanding/2004/cp/b311150d/unauth

2. F. Slemr, G. Schuster and W. Seiler, J. Atmos. Chem., 1985, 3, 407.

3. O. Lindqvist and H. Rodhe, Tellus, 1985, 37B, 136.

4. W. H. Schroeder, K. G. Anlauf, L. A. Barrie, J. Y. Lu, A. Steffen, D. R. Schneeberger and T. Berg, Nature (London), 1998, 394, 331.

5. S. E. Lindberg, S. Brooks, C. J. Lin, K. J. Scott, M. S. Landis, R. K. Stevens, M. Goodsite and A. Richter, Environ. Sci. Technol., 2002, 36, 1245.

6. J. Y. Lu, W. H. Schroeder, L. A. Barrie, A. Steffen, H. E. Welch, K. Martin, L. Lockhart, R. V. Hunt, G. Biola and A. Richter, Geophys. Res. Lett., 2001, 28, 3219.

7. L. Poissant, 2001, personal communication.

8. R. Ebinghaus, H. H. Kock, C. Temme, J. W. Einax, A. G. Löwe, A. Richter, J. P. Burrows and W. H. Schroeder, Environ. Sci. Technol., 2002, 36, 1238.

9. L. A. Barrie, J. W. Bottenheim, R. C. Schnell, P. J. Crutzen and R. A. Rasmussen, Nature (London), 1988, 334, 138.

10. B. T. Jobson, H. Niki, Y. Yokouchi, J. Bottenheim, F. Hopper and R. Leaitch, J. Geophys. Res., [Atmos.], 1994, 99, 23355.

11. P. A. Ariya, B. T. Jobson, R. Sander, H. Niki, G. W. Harris, J. F. Hopper and K. G. Anlauf, J. Geophys. Res., 1998, 103, 13169.

12. P. A. Ariya, H. Niki, G. W. Harris, K. G. Anlauf and D. E. Worthy, J. Atmos. Environ., 1999, 33, 931.

13. W. H. Schroeder and L. A. Barrie, IGACtivities; Newsl. Int. Global Atmos. Chem. Project, 1998, 14, 7.

14. W. H. Schroeder, K. G. Anlauf, L. A. Barrie, A. Steffen and J. Y. Lu, in Proceedings of EUROTRAC-2 Symposium '98, ed. P. M. Borrell and P. Borrell, WIT Press, Southampton, UK, 1999, vol. 2, pp. 358-368.

15. G. C. Compeau and R. Barth, Appl. Environ. Microbiol., 1985, 50, 498.

16. F. Slemr, in NATO-ASI-Series, 2. Environment, ed. W. Baeyens, R. Ebinghaus and O. Vasiliev, Kluwer Academic Publishers, Dordrecht, The Netherlands, 1996, vol. 21, pp. 3384.

17. F. Slemr, E. Brunke, C. Labuschagne, R. Ebinghaus and J. Munthe, Worldwide Trends in Atmospheric Mercury Concentrations, Poster at EUROTRAC-2 Symposium 2002, Garmisch-Partenkirchen, Germany, March 11-15, 2002 .

18. R. Ebinghaus, H. H. Kock, A. M. Coggins, T. G. Spain, S. G. Jennings and Ch. Temme, Atmos. Environ., 2002, 36(34), 5267.

19. Ch. Temme, J. W. Einax, R. Ebinghaus and W. H. Schroeder, Environ. Sci. Technol., 2003, 37, 22.

20. K. W. Oum, M. J. Lakin and B. J. Finlayson-Pitts, Geophys. Res. Lett., 1998, 25(21), 3923.

21. F. Raofie and P. A. Ariya, J. Phys. IV, 2003, 107, 1119.

22. P. A. Ariya and A. Ryzhkov, J. Phys. IV, 2003, 107, 57.

23. P. A. Ariya, A. Khalizov and A. Gidas, J. Phys. Chem. A, 2002, 106, 7310.

24. W. H. Schroeder, G. Yarwood and H. Niki, Water, Air, Soil Pollut., 1991, 56, 653.

25. J. J. S. Tokos, B. Hall, J. A. Calhoun and E. M. Prestbo, Atmos. Environ., 1998, 32, 823 .

26. D. C. Wigfield and S. L. Perkins, Can. J. Chem., 1985, 63, 275.

27. C.-J. Lin and S. O. Pehkonen, Atmos. Environ., 1997, 31, 4125.

28. S. O. Pehkonen and C.-J. Lin, J. AWMA, 1998, 48, 144.

29. J. Sommar, M. Hallquist, E. Ljungström and O. Lindqvist, J. Atmos. Chem., 1997, 27, 233.

30. B. Hall, Water, Air, Soil Pollut., 1995, 80, 301. 
(C) 2004 the Owner Societies (Royal Society of Chemistry)

https://pubs.rsc.org/en/content/articlelanding/2004/cp/b311150d/unauth

31. Å. Iverfeldt and O. Lindqvist, Atmos. Environ., 1986, 20(8), 1567.

32. J. Munthe, Atmos. Environ., 1992, 26A, 1461.

33. V. A. P'yankov, Zh. Obshch. Khim., 1949, 19, 224.

34. P. Biswajit and A. A. Parisa, J. Phys. IV, 2003, 107, 189.

35. E. Bulska, H. Emteborg, D. C. Baxter, W. Frech, D. Ellingsen and Y. Thomson, Analyst, 1992, 117, 657.

36. J. Snell, J. Qian, M. Johanson and K. Smit, Analyst, 1998, 123, 905.

37. A. R. Rickard, D. Johnson, C. D. McGill and G. Marston, J. Phys. Chem. A, 1999, 103, 7656.

38. S. E. Paulson and J. J. Orlando, Geophys. Res. Lett., 1996, 23, 3727.

39. S. E. Paulson, A. D. Sen, P. Liu, J. d. Fenske and M. J. Fox, Geophys. Res. Lett., 1997, 24, 3193.

40. N. M. Donahue, J. H. Kroll, J. G. Anderson and K. L. Demerjian, Geophys. Res. Lett., 1998, 25, 59.

41. W. B. DeMoore, S. P. Sander, D. M. Golden, R. F. Hampson, M. J. Kurylo, C. J. Howard, A. R. Ravishankara, C. E. Kolb, M. J. Molina, Chemical Kinetics and Photochemical Data for use in Stratospheric Modeling, Evaluation number 12, JPL Publication, 1997, 97, 1.

42. R. Atkinson, J. Phys. Chem. Ref. Data, 1997, 26, 215.

43. S. M. Japar, C. H. Wu and H. Niki, J. Phys. Chem., 1974, 78, 2318.

44. F. Kramp and S. E. Paulson, J. Phys. Chem. A, 1998, 102, 268.

45. J. Sommar, K. Gådrfeldt, D. Strömberg and X. Feng, Atmos. Environ., 2001, 35, 3049 .

46. G. Yarwood, H. Niki, A Critical Review of Available Information on Transformation Pathways for Mercury Species in the Atmospheric Environment, Centre for Atmospheric Chemistry and York University, Toronto, 1990.

47. O. Lindqvist, Water, Air and Soil Pollut., 1991, 55, 1. 